\title{
Rejoinder to Letters to the Editor: Luke Wilkinson and Donald McLean, in response to Giovanni Bibbo's letter to the editor: Standardisation of shielding of medical X-ray installations
}

\author{
Giovanni Bibbo ${ }^{1}$
}

Published online: 22 March 2018

๑) Australasian College of Physical Scientists and Engineers in Medicine 2018

In replying to my letter to the editor regarding standardisation of shielding of medical X-ray installations [1], both McLean [2] and Wilkinson [3] indicated that there is a need for the standardisation of shielding in medical practices but the stumbling block is the non-uniformity of radiation safety legislations across local regulatory authorities. With reference to shielding, the lack of uniformity is related to the lack of a shielding standard. The local regulatory authorities do not set standards. Their roles are to enforce standards. In Australia, standards in radiation safety can only be established by ARPANSA with the publication of codes of practice or Standards Australia through AS/NZS documents. As a standard, shielding requirements could be as simple as specifying for each medical imaging modality the thicknesses of the shielding barriers in terms of lead equivalent and the height.

Wilkinson [3] in his reply expressed his concern regarding over-shielding. A simple cost analysis of lead sheets available in hardware stores indicated that there is only a small difference in the costs per square metre of lead sheets of thickness 10,15 and $20 \mathrm{~kg} \mathrm{~m}^{-2}$. This reflects the result of the cost analysis of shielding design performed in 1973 [4] which showed that a tenfold increase in radiation protection could be achieved with only a $25 \%$ increase in cost. This statement was also reported on page 6 of the NCRP 49 [5]. Thus, over-shielding is not an issue as it does not represent an additional huge cost in the shielding of X-ray facilities. Even with the currently used shielding methodologies, in specifying the shielding requirements for an X-ray room, the shielding designer should take into account that the lifetime of clinical use of the $\mathrm{X}$-ray room could be many times that of the initially installed X-ray equipment and the uses of the room and adjacent areas with time are subject to changes. Upgrading the shielding of an existing X-ray room will be much more expensive than if the room was properly shielded from its design stage.

Standardisation of medical X-ray facilities should be the next step in the evolution of radiation protection in Australia and it can only be achieved through organisations such as ARPANSA and Standards Australia with input from the professional societies ACPSEM and ARPS. As mentioned, it is not the responsibility of local regulatory authorities to set standards; their functions are to enforce established standards.

\section{References}

1. Bibbo G (2018) Standardisation of shielding of medical X-ray installations. Australas Phys Eng Sci Med 41:7-8. https://doi. org/10.1007/s13246-018-0619-x

2. McLean D (2018) Reply to letter to the editor: Giovanni Bibbo, Standardisation of shielding of medical X-ray installations. Australas Phys Eng Sci Med 41:9. https://doi.org/10.1007/s1324 6-018-0625-z

3. Wilkinson L (2018) Reply to letter to the editor: Giovanni Bibbo, Standardisation of shielding of medical X-ray installations. Australas Phys Eng Sci Med 41:11. https://doi.org/10.1007/s1324 6-018-0626-y

4. Braestrup CB, Wyckoff HO (1973) Shielding design levels for radiology departments. Radiology 107:445-447

5. National Council on Radiation Protection and Measurements (NCRP). Structural shielding design and evaluation for medical use of X-rays and gamma rays of energies up to $10 \mathrm{MeV}$. NCRP Report No. 49,1976. Bethesda, Maryland
Giovanni Bibbo

giovanni.bibbo@sa.gov.au

1 SA Medical Imaging, Women's and Children's Hospital, North Adelaide, SA, Australia 